\title{
Revitalização cultural e educação popular no bairro de Itapuã, Salvador, Bahia: o protagonismo dos "itapuanzeiros"
}

Débora Matos Maia1, Pedro Rodolpho Jungers Abib²

\begin{abstract}
Resumo
O presente artigo busca compreender o processo educativo de reconstrução cultural da comunidade de Itapuã, em Salvador, Bahia, a partir das dinâmicas culturais locais, tomando como recorte do campo investigativo o processo de revalorização das manifestações tradicionais, levado a cabo por uma parcela organizada dos moradores, que se autodenominam "itapuanzeiros". Essa investigação buscou captar a singularidade da cultura local, como também compreender os sentidos e significados dessa retomada das tradições para e pela comunidade de Itapuã do ponto de vista da educação e da identidade, focando nas aprendizagens que se dão no contexto das manifestações culturais no bairro. A metodologia foi desenvolvida a partir de estratégias etnográficas como a observação participante, entrevistas, gravações em audiovisual e diário de campo. No referencial teórico, foram utilizados autores como Milton Santos, Castells, Magnani, Chauí, Certeau, Boaventura de Sousa Santos, Hall, Vygotsky e Paulo Freire.
\end{abstract}

\section{Palavras-chave}

Revitalização Cultural. Comunidade. Identidade. Educação Popular.

1. Doutoranda em Educação na Universidade Federal da Bahia, professora na rede municipal de educação de Salvador, membro do Grupo de Pesquisa Griô e moradora do bairro de Itapuã, Salvador-BA. E-mail: deboramatosmaia@gmail.com.

2. Pós-Doutor em Ciências Sociais pela Universidade de Lisboa, professor titular da Universidade Federal da Bahia, coordenador do Grupo de Pesquisa Griô e morador do bairro de Itapuã, Salvador-BA. E-mail: pedrabib@ gmail.com. 


\title{
Cultural revitalization and popular education in the neighbourhood of Itapuã, Salvador, Bahia: the role of "itapuanzeiros"
}

Débora Matos Maia*, Pedro Rodolpho Jungers Abib**

\begin{abstract}
This paper aims to investigate otherness relation between orality and writing and his value under a perspective of a literacy discourse. Tfouni (2009) and Pereira (2009) discuss that this is important to the interpreters of the subject due to the symbolic strength of the writing discourse. Accordingly to Belintane (2011), the orality is understood by means of a notion of esthetic of a game and discussed under his exclusion in language teaching in the school. Thus, we analyze oral remarks as they appear in the discursive sequences of round song of a remnant maroon community of south-west of Bahia state. The methodology is based on Serrani (1997) and the notion of discursive sequence. We discuss the possibilities of the first language dialogue with the orality of a locale.
\end{abstract}

\section{Keywords}

Oral Tradition. Literacy. Maroon. Samba. Popular Culture.

\footnotetext{
* PhD in Education, Federal University of Bahia, State of Bahia, Brazil; teacher in municipal education of Bahia, Griô Research Group; resident in Itapuã, Salvador, State of Bahia. E-mail: deboramatosmaia@gmail.com.

** Post-doctorate in Social Science, Lisboa University, Portugal; professor at Federal University of Bahia, State of Bahia; coordinator of the Research Group Griô; resident of Itapuã, Salvador, State of Bahia. E-mail: pedrabib@ gmail.com.
} 


\section{Introdução}

Este artigo é fruto de uma pesquisa em que foram utilizadas estratégias etnográficas, como o diário de campo, observação participante, além de entrevistas e gravações em audiovisual. Vale ressaltar que todos os entrevistados assinaram autorização para que pudéssemos divulgar suas falas e imagens. Por que a escolha do bairro de Itapuã? Ambos os pesquisadores são residentes dessa região, uma é moradora do local desde seu nascimento e o outro reside no bairro há mais de 20 anos, oriundo do estado de São Paulo.

A inspiração que deu origem à pesquisa, que ora apresentamos neste artigo, foi a investigação sobre a retomada das tradições locais, que tem relação com todo um processo educativo, endoculturativo, ou seja, de aprendizagens a partir da convivência com a cultura de um lugar, no caso, o bairro de Itapuã, localizado na cidade de Salvador, Bahia. Esse local demarca referências poéticas advindas das obras de cantores, compositores, artistas plásticos, cineastas, entre outros, atribuindo a ele um caráter bastante representativo do imaginário sobre a cultura da Bahia presente dentro e fora do Brasil.

Inicialmente habitada por índios, durante a escravidão, esse lugar foi um importante quilombo - o Buraco do Tatu - registrado por historiadores. Passou a ser uma fazenda e, posteriormente, uma vila de pescadores que tinha a pesca da baleia como sua principal fonte de sobrevivência. Sofreu e vem sofrendo um crescimento urbanístico acelerado e, em decorrência disso, a paisagem, o espaço, o lugar, as relações sociais e as manifestações culturais que constituem a identidade local têm passado por importantes transformações, a partir da especulação imobiliária e da influência do grande fluxo de novos moradores que têm se instalado no bairro.

A abordagem sobre educação popular se faz presente neste artigo ao explicitar a cultura popular como um meio para formação dos seres humanos, valorizando os saberes que surgem durante as vivências cotidianas e compondo uma trajetória que engloba as relações humanas de aprendizados transmitidos de um indivíduo para o outro, ressignificados de geração em geração, e que também se constituem em aprendizados socioculturais, resultado da expressão e história de formação humana por meio do envolvimento com as manifestações culturais e sua comunidade.

Desse modo, buscamos compreender o processo educativo de reconstrução cultural da comunidade de Itapuã, a partir das dinâmicas culturais locais, tomando como recorte do campo investigativo o processo de revalorização das manifestações tradicionais levado a cabo por uma parcela organizada dos seus moradores, que se autodenominam "itapuanzeiros" 3 .

Essa investigação procurou captar a singularidade da cultura local - o que há de simbólico expresso pelas tradições - como também o intangível, o valor imaterial, aquilo que não se pode mensurar e que está nas relações de ajuda mútua, na qual cada membro do grupo se predispõe a utilizar seu capital intelectual e sua força de trabalho para colaborar com o coletivo, mesmo com toda a transformação pela qual o lugar tem passado. Para Castells (1999, p. 79),

as pessoas resistem ao processo de individualização e atomização, tendendo a agrupar-se em organizações comunitárias que, ao longo do tempo, geram um sentimento de pertença e, em última análise, em muitos

3. Termo valorizado na maioria das falas dos atores sociais, sendo repleto de sentidos e significados que serão aprofundados durante o texto e que é atribuído ora aos nascidos em Itapuã, ora às pessoas que possuem sentimento de pertencer ao lugar. 
casos, uma identidade cultural, comunal.

Para que isso aconteça, o autor explica que é preciso mobilização social, revelando interesses em comum e, de algum modo, compartilhados.

Em Itapuã, a comunidade do bairro vem discutindo e se articulando diante das ameaças, orientando suas ações para valorizar aquilo que julgam ser importante para a preservação da identidade local. Os processos identitários protagonizados por grupos sociais - tais como o exemplo que ora apresentamos, a comunidade de Itapuã - são formas de resistir a esse movimento homogeneizador e têm, na intersecção entre educação e cultura, a convergência de práticas fundamentais para a ressignificação desses processos. Assim, por meio da cultura, é possível pensar em uma educação que leva em consideração o ser humano a partir de seu cotidiano, suas dificuldades, necessidades e solidariedades resultantes de aprendizagens culturais locais que influenciam tais processos identitários.

As formas de mobilização proporcionadas pelos elementos da cultura local - festas, manifestações, festivais, celebrações, eventos, mutirões, entre outros-podemser extremamente importantes para a conscientização desses grupos sobre sua identidade e capacidade de operar as transformações que julgam ser necessárias no seu cotidiano, uma vez que começam a compreender a força de seu coletivo e as possibilidades de intervenção na realidade que isso representa.

Surge, assim, o seguinte questionamento: quais os sentidos e significados das tradições para a comunidade de Itapuã do ponto de vista da educação e da identidade, focando as aprendizagens no contexto das manifestações culturais do bairro? Para isso, foi preciso compreender a identidade itapuanzeira a partir das características, saberes, história, valores e costumes do lugar. Fez-se necessário interpretar, também, a partir dos sentidos veiculados pelos atores sociais pesquisados, as tensões entre as expressões culturais e os ideários formativos vividos por eles. A partir disso, buscamos, então, verificar as práticas educativas ligadas a esses eventos que perpassam o envolvimento da comunidade nas expressões da cultura local, enquanto ações dos moradores do bairro envolvidos com $\mathrm{O}$ fortalecimento e reconstrução das identidades.

\section{Sentido de identidade e pertencimento: 0 itapuanzeiro}

Vários são os eventos culturais do bairro de Itapuã, sobretudo aqueles que envolvem locais tradicionais, alguns deles, inclusive, implicam em intimidade com os protagonistas desse fazer cultural local. Embora as portas estejam sempre abertas a novos visitantes, eles devem ser trazidos por alguém já "iniciado" nessas ações culturais. Os laços comunitários assim se estabelecem e se fortalecem, permeando alguns desses fazeres e saberes locais. Dessa forma, e cientes dessas peculiaridades, passamos a frequentar mais assiduamente alguns desses eventos, como os sambas e as rezas na casa de Dona Cabocla e no bar de Seu Reginaldo; os bate-papos musicados na beira da Lagoa do Abaeté; os saraus na Casa da Música; as caminhadas da lua cheia nas Dunas do Abaeté; a Festa de São Tomé; o Bando Anunciador da Lavagem de Itapuã, seguido do café da manhã na casa de Dona Nissú; o samba no antigo mercado, regado à cachaça de ervas de seu Toinho; o "arrumadinho" do Bar de Mamão ou, simplesmente, apreciar o pôr do sol na Barraca de Juvená.

A partir da vivência diária no seu cotidiano, ao longo de alguns anos, foram se estabelecendo laços mais profundos com esses protagonistas locais, em que pudemos, aos poucos, acessar histórias sobre o lugar e sobre pessoas importantes, vivos na memória e no imaginário desses sujeitos, ao mesmo tempo em que também passamos a observar e cruzar as informações ouvidas, sentidas e 
percebidas, como a fala de Seu Reginaldo, compositor que narra com beleza e poesia coisas de Itapuã. Quando perguntado sobre a inspiração para suas composições, ele diz:

Vem daqui mesmo. Do contato com o povo. Cada cena que eu vejo pode virar uma composição. Eu tenho música que fala dos vizinhos, da escola de samba Unidos de Itapuã, das Ganhadeiras de Itapuã, do Abaeté, da época que existia a "Loba", um ônibus que fazia o trajeto do centro até Itapuã pela areia da praia... até essa nossa conversa pode virar música. A cultura daqui me inspira!

$\mathrm{Na}$ atmosfera cotidiana, existe tanto o contato direto com a poluição sonora, excesso de carros, ônibus, pouca presença da natureza, quanto também ambientes tranquilos, com crianças brincando nas ruas, cavalos soltos, chão de barro, árvores e sons de passarinhos. Hoje, embora seja um polo de atração turística, Itapuã tem se consolidado principalmente como bairro de residência. A sua paisagem é mesclada: entre as belezas naturais (praias, dunas e lagoas) estão prédios, casas de pescadores antigas, casas com arquiteturas modernas, condomínios e favelas (as chamadas "Baixas" do Dendê, da Soronha etc.).

A vida nas "baixas" se assemelha a das favelas nos morros, na qual os espaços são restritos, as ruas são utilizadas como extensões das casas, a população é pobre, em sua maioria negra, e a infraestrutura dos espaços é precária. A origem dos moradores é diversificada, sendo, muitos deles, advindos do interior da Bahia. Eles têm em comum a mesma condição financeira e/ ou a cor da pele, herança dos povos indígenas e africanos. Locomovem-se constantemente a pé, de bicicleta ou de transporte coletivo e mantêm vínculos de solidariedade fortes devido às semelhantes dificuldades as quais a maioria está sujeita.

Ao mesmo tempo, existem ruas, "intrabairros" de classe média, constituídos por uma grande quantidade de condomínios, nas quais os moradores não têm contato próximo com a efervescência cultural que o bairro de Itapuã dispõe e muito menos com a realidade que estes intrabairros das "baixas" possuem. São, em sua maioria, complexos de novos condomínios de casas e pequenos prédios que oferecem "área de lazer" e toda uma infraestrutura. Os moradores de classe média têm outra cultura e outras referências de formação étnica. Em sua maioria, possuem meios de locomoção próprios e mantêm seus vínculos sociais com pessoas espalhadas por toda a cidade, a depender das instituições e locais que frequentam, dificultando, dessa maneira, a criação de um vínculo identitário com o lugar. A maioria desses moradores não estabelece uma relação mais próxima com os eventos e manifestações culturais que existem em Itapuã, que acontecem principalmente dentro da faixa destacada destacada na figura abaixo, e essa centralização contribui para o fortalecimento cultural e identitário na região. 
Figura 1 - Itapuã: localização.

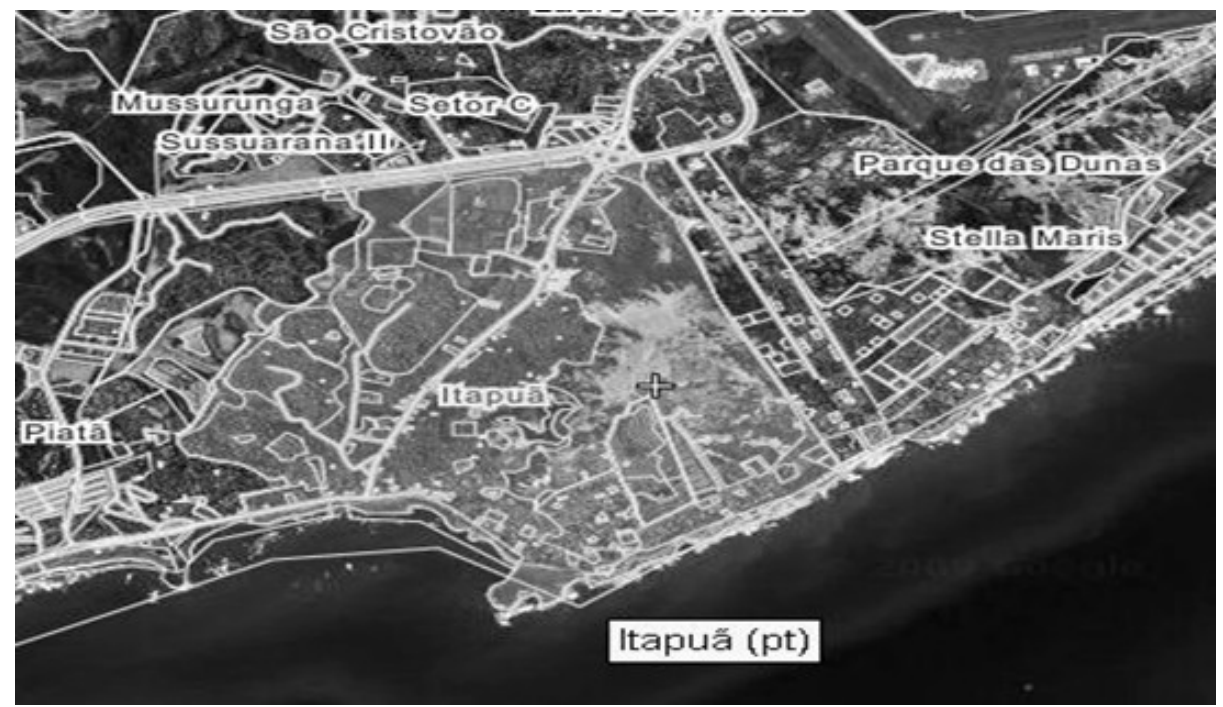

Fonte: Google (2014).

A nova organização espacial de Itapuã tem influenciado tanto no cotidiano quanto nas tradições culturais de sua comunidade, pois, com a chegada de uma grande quantidade de pessoas advindas de outros lugares, sem aproximação com a história e cultura locais, o bairro se vê em processo de vertiginoso crescimento sem que haja uma preparação para receber tantos "forasteiros". Disso decorre o seguinte questionamento: de que forma as transformações no local têm interferido na dinâmica sociocultural dos moradores e na manutenção dos seus costumes?

Temos que a antiga organização social local foi modificando-se devido ao lugar receber pessoas de todas as classes socioeconômicas, transformando-se, assim, em um dos maiores bairros da cidade. Por outro lado, o bairro ainda conta com uma comunidade que tem fortes identificações com o lugar e procura discutir e se organizar em função do fomento à identidade itapuanzeira. Esse processo de crescimento foi demasiadamente acelerado, influenciando decisivamente as relações sociais no bairro, sobretudo no que diz respeito às atitudes dos moradores mais antigos. Certa vez, em um samba na Casa de Dona Cabocla, a pesquisadora Débora foi questionada sobre ser ou não itapuanzeiros. Esta pergunta intrigou a pesquisadora a buscar descobrir junto a Pedrão o sentido e significado dessa palavra. Abaixo um fragmento do seu diário de pesquisa (2010):

\footnotetext{
Hoje no Samba de Dona Cabocla, ao chegar e cumprimentar alguns presentes, veio um rapaz me perguntar se eu morava mesmo em Itapuã, argumentando que nunca havia me visto pelo bairro. Neste momento, tive dificuldade de respondê-lo, pois não moro no coração de Itapuã, mas em um dos seus intrabairros. Expliquei que não tinha o costume de viver Itapuã como um todo, tudo que o lugar oferece, mas apenas alguns locais que se faziam necessários a partir da minha rede social, que não era grande e nem se encontrava, até então, articulada com a comunidade ligada às tradições do lugar. Disse: "sou nativa porque nasci e me criei aqui, em um pedaço do bairro, vivi uma parte, não ele por completo". Apesar de ser "nativa", sempre fui frequentadora de tantos outros lugares além de Itapuã, além de Salvador...
} 
E o Pedrão, embora nascido em São Paulo e morador de Itapuã há mais de 20 anos, poderia ser considerado um itapuanzeiro? Éramos ou não itapuanzeiros? E que diferença fazia ser ou não nativos? Passamos então a perceber a forte relação identitária que havia na denominação itapuanzeiro(a) nativo(a). Castells (1999, p. 23) vai nos dizer que "toda e qualquer identidade é construída", sendo a questão intrigante descobrir "como, a partir de que, por quem e para que isso acontece".

O papel dos autores deste texto nesse processo possui duas vias. Débora atuando como investigadora, conhecendo e sendo conhecida nos encontros com a comunidade ligada às manifestações culturais, foi aos poucos se envolvendo. Primeiramente propondo ações no ponto de cultura Casa da Música, dando aulas gratuitas de dança e ginástica no ano de 2010 e, posteriormente, organizando a "Caminhada nas Dunas do Abaeté", com intuito de ocupar e dar acesso ao lugar que estava sendo esquecido devido à violência e insegurança. Pedrão começou a fazer ações no campo da cultura local, instituindo um samba no mercado de Itapuã, em 1997, valendo-se dos seus dons artísticos de tocar e cantar. Este é conhecido e respeitado na comunidade por organizar uma série de eventos culturais no bar Rumo do Vento, na casa de Dona Cabocla e como já foi dito, no antigo Mercado de Itapuã, que está passando por uma reforma. Dessa forma, ambos os pesquisadores participam ativamente da comunidade itapuanzeira, sendo um desafio aproximarem-se, cada vez mais, de todo processo organizativo dos movimentos culturais.

Com isso, qual a relação a palavra itapuanzeiro(a) tem com a transformação do bairro? Primeiramente, é preciso compreender esse termo cheio de significados e valores confusos, ligado ao sentimento de pertencer, que inicialmente era designado às pessoas que nasciam no lugar e que tem sofrido ressignificação de seu conceito com as atualizações pelas quais o bairro, a cidade e o mundo passaram e continuam passando.

Para responderaoquestionamento pontuado mais acima, selecionamos sujeitos implicados com a cultura local para entrevistarmos, 13 no total, tomando como referência Freire (2005, p. 141), quando diz:

os que são considerados em nível de liderança nas comunidades, para que assim sejam tomados, necessariamente, refletem e expressam as aspirações dos indivíduos da sua comunidade.

Os sujeitos da entrevista são como ícones, personalidades de referência para a cultura local, sendo "poços" de saberes populares locais, articuladores e mediadores culturais. São compositores, ativistas culturais, representantes de grupos culturais locais, enfim, pessoas que contribuem para a manutenção e perpetuação das tradições e história do lugar.

O contato com os entrevistados foi feito antecipadamente e combinado um dia para cada entrevista. Quase todas aconteceram em suas residências, exceto no caso de Amadeu Alves, que foi na Casa da Música, seu local de trabalho. Fomos muito bem recebidos nas entrevistas, lanches fizeram parte dos encontros e os entrevistados faziam questão de mostrar músicas, fotos e objetos dos seus acervos pessoais. A grande troca de saberes se deu em cada encontro e nós pesquisadores passamos a ser cobrados a darmos um retorno para a comunidade.

\section{Os itapuanzeiros}

Na trajetória, identificamos alguns tipos de itapuanzeiros: os que nasceram e têm sua raiz genealógica ligada à história de Itapuã; os que nasceram em Itapuã, mas possuem sua história familiar construída em outros lugares da cidade, do interior da Bahia ou fora destes 
perímetros; os que não chegaram a nascer em Itapuã, mas escolheram fixar sua residência no lugar; e até aqueles que se mudaram para tentar a vida em outro lugar. Alguns termos são adicionados e utilizados para fazer a diferenciação como nato, nativo, transplantado e agregado, podendo ser percebidos nas falas de Biriba, 33 anos, professor de capoeira, nascido em Itapuã. Ele descreve o itapuanzeiro nato:

Ser itapuanzeiro é você respirar esse mar na beira da praia, comer um peixe, ter essa malandragem que o bairro oferece, essa maresia e ao mesmo tempo os caras são guerreiros, está sempre driblando as dificuldades. Você vê que hoje os órgãos competentes virou as costas pro bairro, mas não é por isso que o bairro deixou de caminhar com todas as dificuldades.

Porém, o termo "itapuanzeiro" para alguns não deveria ter relação com o nascimento, como afirma Seu Reginaldo, ou simplesmente Seu Regi, um excelente compositor de samba, perto de seus 70 anos, 38 dos quais vividos em Itapuã, dono de um dos importantes espaços de convivência cultural do bairro - o bar Rumo do Vento. Diz ele:

Aqui o pessoal chama itapuanzeiro quem nasce em Itapuã. Eu gostaria que itapuanzeiro fossem as pessoas que zelam por Itapuã, que divulgam o nome de Itapuã para o bem. Essas pessoas eu acho que deveriam ser chamadas de itapuanzeiras, que gosta e que zela pelo bairro. Porque tem muitos itapuanzeiros que não zelam por Itapuã, não têm nenhum cuidado, então não deviam ser chamados de itapuanzeiros. Itapuanzeiro deveria ser realmente as pessoas que se dedicam, que divulgam o nome do bairro na cultura, na educação, em qualquer parte, no esporte, qualquer coisa e até na conservação também, esse eu acho itapuanzeiro, na minha opinião. Mas aqui se entende itapuanzeiro quem nasce em Itapuã.

Assim, mesmo o indivíduo não sendo necessariamente nascido e criado em Itapuã, este poderia, na visão de Seu Regi, ser caracterizado como itapuanzeiro, desde que existisse uma forte implicação com o lugar. Para Celso, músico nascido no bairro, o termo não deveria ser esse, mas sim itapuoense. Continua ele:

Ser itapuanzeiro é o seguinte, é você saber viver a cultura do bairro. Uma pessoa que vem de fora não pode chegar e abrir a boca e dizer que é itapuanzeiro, não pode. Porque o itapuanzeiro ele chega ali na praia, ele tira uma pinaúna, ele come a pinaúna ali mesmo, ele vai no mercado, toma uma e não deixa de cumprir a sua responsabilidade com a sua família. [...] hoje não dá mais pra ser itapuanzeiro assim 100 \% não porque o negócio está meio diferente.

Nesse momento, mais uma vez, as mudanças são trazidas para explicar a atualização identitária dos moradores locais. Dessa maneira, as transformações fazem parte da realidade das sociedades atuais e têm trazido como consequência processos identitários em que os indivíduos não mais se veem como seres sólidos e fixos, mas fragmentados e dispersos a depender de cada momento e ambiente. Essa convivência com a pluralidade cultural contribui para que identificações com outras culturas aconteçam, no entanto, esse fato tem resultado no que Hall (2006) chama de "crise de identidade", como consequência da globalização.

Assim, os processos identitários vão se multiplicando por todas as partes do planeta. O globaleolocal secontrapõemesecomplementam simultaneamente e as narrativas produzidas no próprio bairro de residência vão ganhando significado. Isso se dá por meio de uma ligação com o lugar, que vai sendo construída com as vivências no cotidiano local, a comunicação entre os moradores e a criação de vínculos.

Dessa forma, mesmo que o indivíduo não pertença à história do lugar, seja um novo morador, mas que se identifica com este a partir 
da aproximação com sua narrativa, pode-se ter, então, um deslocamento que possibilite articulação com suas diversas outras identidades. Segundo Hall (2006, p. 76), estas são

vínculos a lugares, eventos, símbolos, histórias particulares. Representam o que algumas vezes é chamado de uma forma particularista de vínculo ou pertencimento.

Se, por um lado, ser itapuanzeiro demonstra um sentimento de pertencimento e impulsiona ações no sentido de cuidar do lugar, por outro, para aqueles que chegam, pode representar espinhos que machucam a identificação que está sendo construída pelos novos moradores frente ao lugar, podendo levar a um afastamento e recolhimento ao invés da aproximação. Amadeu, 45 anos, músico e compositor, nascido e criado em Itapuã, vai alertar sobre isso, dizendo que é importante cultivar o termo itapuanzeiro para que as pessoas saibam que existe essa identidade cultural e que esse traço identitário, que envolve um jeito de ser, ainda está vivo. No entanto, com toda a complexidade e emaranhado da diversidade alertam que, ao mesmo tempo, é preciso tomar cuidado para não segregar:

Itapuanzeiro basicamente a gente vê assim, aquele nativo do bairro, uma pessoa realmente que nasceu aqui no bairro. E é também uma forma de definição que a gente deve tomar cuidado também pra não segregar. Aí algumas pessoas se acharem itapuanzeiros e até se sentirem com algum direito a mais do que os outros num lugar que hoje realmente é uma multiplicidade tão grande e que existem pessoas que se agregaram a ele e às vezes dão contribuição bem maior às vezes do que alguns outros que se acomodaram e perderam.

Essa fala nos faz pensar se ser ou não itapuanzeiro é um fator que dificulta a aproximação dos recém-chegados moradores. Choque de culturas, de costumes, de jeitos de pensar e agir. Esses podem contribuir para que muitas pessoas, que passaram a habitar o espaço, não se envolvam verdadeiramente com o lugar. Sempre muito desconfiados, os itapuanzeiros demoram em aceitar forasteiros e até mesmo aqueles moradores que não fazem parte da pequena teia comunitária ligada às tradições. Para Ulysses, 70 anos, pescador nativo de Itapuã, pedreiro e fundador de vários grupos culturais, a questão é a pessoa se dar bem na terra que escolheu para morar:

Porque eu nasci em Itapuã, eu sou dono de
Itapuã? Não. Sou mais um componente de
Itapuã. Agora eu por ser mais um componente
eu preciso me respeitar, pra respeitar os
demais pra eu ser respeitado. Não é porque
eu nasci aqui, você não nasceu, eu vou
começar a pisar você, "quem é você, você
não é daqui de Itapuã!". Isso pra mim é uma
grande bobagem que falam. Itapuã pra mim,
a terra é o lugar que a gente se dá bem. Eu me
dou bem ali, eu sou filho dali.

A questão da identificação com o lugar é o ponto principal, junto com o respeito ao que já existe, com a natureza, a cultura do lugar, no qual as pessoas podem se identificar com algumas características e outras não. Mesmo assim, um fato que não pode ser esquecido é a ligação que essas manifestações culturais têm com a formação do povo brasileiro, oriundas do encontro de culturas e que se mantêm vivas devido à contribuição fundida e mantida por meio das tradições constantemente atualizadas. Amadeu afirma que,

Pra contar a história cultural do bairro, que passa pela festa de Itapuã, que passa por essas manifestações artísticas e culturais populares e tudo mais, não dá pra contar sem falar das diversas contribuições, seja do afrodescendente, seja do caboclo, seja do mameluco, do branco, do mulato, quer dizer, essas contribuições aconteceram bem efetivamente e dentro de Itapuã. Sem dúvida nenhuma a cultura continua viva 
por conta dessas contribuições. São relações de identidade mesmo, algumas pessoas se identificam mais com uma ou com outras e ai a gente tem que compreender isso.

Dessa forma, para possuir o sentimento de pertença e ser reconhecido por sua comunidade como tal, leva tempo de convivência, ações e observações mútuas e as tradições aparecem como uma forma de agregar e unir a população. As falas mostram que o termo "itapuanzeiro" tem passado por um processo de ressignificação no sentido de tentar abraçar e valorizar não apenas os que nasceram no bairro, mas também aqueles que desenvolveram um sentimento de pertencimento ao lugar. Mais do que isso, ser itapuanzeiro significa valorizar as tradições do lugar, a partir do esforço de cada um em manter vivas as festas, manifestações, os personagens, as históriaseasmemórias. Dessaforma, osentimento de pertença é reforçado a cada celebração, a cada momento em que esses sujeitos se reúnem para cantar, tocar, dançar, comer e beber. Amadeu, ao abordar aspectos comunitários, educativos, históricos e da cultura popular, como a memória e a ancestralidade, para explicar como cultivar esse sentimento, se utiliza de metáforas e se baseia na natureza, como é comum na cultura popular, para explicar fatos e acontecimentos:

O que é que vai buscar a nutrição numa árvore, por exemplo, são as raízes, então a árvore vai buscar na terra os nutrientes e a água onde vai lá se aprofundando e a gente não vê. Esse trabalho da raiz a gente não vê, fica ali invisível. Mas é o que leva todo esse nutriente, a seiva pelo tronco da árvore, pelos galhos, até chegar nas folhas. A folha recebe também a luz do sol. Então, é um processo que ao mesmo tempo em que você tem que olhar pra frente, você também tem que olhar pra trás. Você tem que ir buscar nas pessoas mais antigas do bairro... e pra alguém que quer realmente cultivar isso, ela vai olhar essas pessoas com uma referência muito valiosa, porque são os tesouros, guarda a memória. É a comunicação e a atitude e o gesto de estar presente... não só sugar, mas tem que também estar contribuindo, oferecendo.

O cultivar requer vivência, manutenção, cuidado, solidariedade para que novos frutos venham a crescer e se multiplicar. Nesse caso, a festa, o culto, a música e a dança são formas de celebrar a convivência, independente de onde eles vieram ou nasceram, como também ajuda a desenvolver um sentimento de pertencimento ao lugar.

Dessa maneira, dizer que uma pessoa passou a se tornar itapuanzeiro começa a fazer sentido a partir do momento em que esta passa a ter envolvimento com os saberes, os fazeres, os sujeitos, os lugares, as memórias, as festas, como também aprender a conviver e partilhar das construções e reconstruções cotidianas, desenvolvendo um sentimento de pertencimento que começa a influenciar diretamente os processos identitários de cada um. Dessa maneira, começamos a compreender o que é ser itapuanzeiro sendo, vivenciando, comendo e bebendo, cantando e dançando Itapuã, como diria Freire (2008, p. 19), se "ensopando" das histórias e personagens do lugar, ouvindo atentos os ruídos e sons, palavras e melodias, decifrando gestos, olhares, sorrisos e trejeitos. Internalizando signos a partir da convivência com esse contexto, em uma aprendizagem cultural constante. Sínteses criativas acompanham esse processo em todos os momentos, mas vamos nos ater aqui a uma questão que nos parece vital para compreendermos melhor os processos identitários recentes que têm mobilizado e inspirado os moradores de Itapuã: qual a relação entre a identidade itapuanzeira e o processo de revitalização das manifestações culturais em curso na atualidade? 


\section{A revitalização das manifestações culturais de Itapuã}

A sobrevivência das manifestações culturais está ligada às modificações e transformações sofridas por elas ao longo dos anos, pois a dinâmica social implica que as tradições vão se transformando à medida que as sociedades que as produzem também se transformam, como nos diz Hobsbawm (1997). A diferença entre tradição e costume é discutida por este autor, sendo que a tradição inventada possui a característica de imposição de práticas fixas, como repetições, enquanto o costume não tece impedimento para que a própria dinâmica social implique em inovação e modifique as práticas culturais.

Quando a antropologia migra para o estudo dos contextos urbanos na modernidade, marcados pela heterogeneidade, multiplicidade de costumes e práticas, passa a desafiar a nós pesquisadores, que direcionamos o nosso olhar e fazer antropológicos no sentido de estabelecer ligações entre o passado e o presente, buscando compreender as estratégias dos sujeitos perante as suas realidades (VELHO, 1997).

Dessa forma, o bairro de Itapuã, ao passar por modificações e influências externas, vem transformando costumes e criando outros. Isso porque alguns membros da comunidade, preocupados com tantas mudanças, passaram a agir na tentativa de preservar traços identitários que julgam ser importantes, que passam pela percepção da necessidade do fortalecimento das manifestações culturais locais, criação de grupos e eventos culturais, revitalização de espaços, até a própria valorização das atividades comerciais.

Para Santos (2009, p. 115), a contraordem pressupõe uma racionalidade oposta ao pensamento dominante, que o autor chama de "irracionalidades", mantidas e produzidas pelos que estão "embaixo". A partir delas, a consciência pode ser ampliada, e o pensamento crítico pode se desenvolver, possibilitando novas formas de interpretar o mundo e as relações das quais são protagonistas.

Diante desse contexto, em um dado momento, descontentes com o desinteresse que a população local vinha demonstrando em relação às festividades tradicionais, algumas lideranças comunitárias passaram a realizar ações no sentido de fortalecer a cultura no bairro. É criado, então, o grupo Mantendo a Tradição, do qual Dona Francisquinha, hoje falecida, foi uma das fundadoras. Dona Francisquinha exerce um papel muito forte no imaginário da comunidade de Itapuã, pois ela é a referência desse processo de revitalização cultural pelo qual passa o bairro atualmente. Até hoje, mesmo depois de sua morte, uma festa na data de seu aniversário é organizada no Largo do Jenipapeiro, local onde residia. Realiza-se uma grande celebração comunitária que fortalece a identidade itapuanzeira, com a presença de grupos culturais, escola, associação e moradores.

Figura 2 - Dona Francisquinha e Seu Menezes em um carnaval em Itapuã.

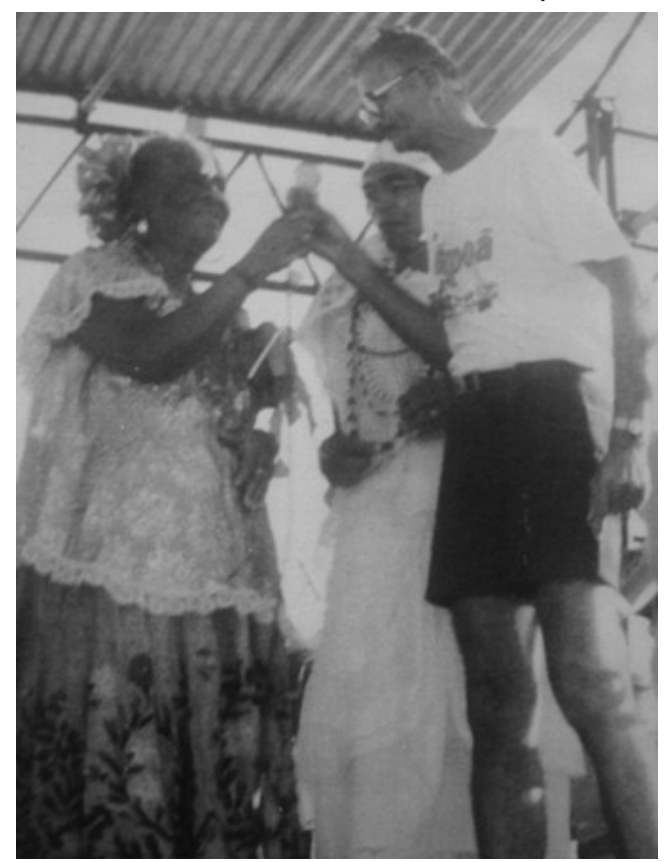

Fonte: Arquivo pessoal de Seu Menezes (1987). 
Foi o grupo fundado por Dona Francisquinha que deu o primeiro passo para que se iniciasse a reconstrução cultural em Itapuã de maneira mais clara. Alguns fatores foram decisivos para a dispersão de algumas tradições e "irracionalidades" (SANTOS, 2009) no bairro, que têm ligação com o que se passava no país e no mundo, principalmente na década de 1980, com o aumento significativo da influência dos meios de comunicação de massa sobre a sociedade brasileira.

Acontece que nem todos os moradores do bairro se deixaram levar pela "onda" da indústria cultural, que trazia a valorização de outras culturas em detrimento da "cultura nativa", termo utilizado pelos moradores em referência à cultura local. Foi então que se iniciou esse processo de revalorização das tradições locais, que acabou influenciando outros moradores a fazerem o mesmo. Em 1997, é criado o Grupo de Revitalização de Itapuã (Grita), buscando por meio das pessoas que mantinham ligação com a história do bairro, como os antigos moradores, lavadeiras, pescadores e contadores de história - ir ao (re)encontro dessas tradições.

Santos (2009) afirma que há um movimento vertical e homogeneizador conduzido por um mercado cego que impõe elementos da cultura de massa. No entanto, diz ele que esse processo não chega a se completar totalmente, pois encontra resistência das culturas locais. Essa mobilização toda estava acontecendo no bairro de Itapuã, em oposição a uma tendência global de homogeneização, em que uma pequena resistência estava disposta a fazer a história acontecer, inspirando-se nas tradições locais.

Com isso, a comunidade de Itapuã passa a reagir, buscando reconstruir, revitalizar os eventos e manifestações culturais locais a partir de um esforço das "lideranças" em organizar, apoiar e desenvolver eventos mobilizadores de sujeitos, por meio de táticas diversas com intuito estratégico de fortalecer as raízes identitárias e comunitárias a partir da cultura. Bhabha (2005, p. 44), ao falar sobre o valor e a importância de uma política de produção cultural, nos diz que "as formas de rebelião e mobilização popular são frequentemente mais subversivas e transgressivas quando criadas por práticas culturais oposicionais". Nessa direção, afirma Magnani (2003, p. 26) que:

\begin{abstract}
Mais relevante que lamentar a perda de uma suposta autenticidade, no entanto, é tentar analisar as crenças, costumes, festas, valores e formas de entretenimento na forma em que se apresentam hoje, pois a cultura, mais que uma soma de produtos, é o processo de sua constante recriação, num espaço socialmente determinado.
\end{abstract}

Sem a intenção de criar padrões conceituais, mas na tentativa de compreender as manifestações culturais em Itapuã, arriscamos apontar algumas características dos eventos que acontecem atualmente, trazendo essa marca da resistência e valorização das tradições locais:

a. Aqueles mais focados na memória com repetição de rituais mais antigos ou que relembram fatos históricos locais, como o dia de São Tomé em Itapuã, uma tradição muito antiga no bairro e que, há alguns anos, voltou a ser comemorada com um cortejo pela orla em direção a Piatã. Supostamente, dizem as histórias dos moradores, nesse local, foi cravejada em uma pedra, na areia da praia, uma cruz por São Tomé (essa suposta marca pode ser encontrada no local), onde acontecem rezas e comemorações regadas a comidas, bebidas e muita música. Também as manifestações que eram tradicionais no calendário do bairro e que ficaram um bom tempo esquecidas, mas, nos últimos anos, foram retomadas com muito vigor, como o Terno de Reis, os Ranchos, o Bando Anunciador da Lavagem de Itapuã e o Presente de Yemanjá. Ainda, a Festa da Baleia, na quarta-feira de cinzas, 
com uma réplica em tamanho natural das antigas baleias pescadas no local;

b. Aqueles voltados para a celebração ou homenagem a símbolos religiosos ou pessoas importantes para o lugar, em que o ritual e a ancestralidade estão fortemente presentes, como o dia de homenagem à Dona Francisquinha em Itapuã, a Trezena de Santo Antônio na casa da centenária dona Cabocla e o dia de São Lourenço no bar Rumo do Vento de Seu Reginaldo;

c. Aqueles que unem festa, música, dança e comida, como o Aniversário d'As Ganhadeiras de Itapuã, grupo cultural que remonta à memória musical do antigo ofício das mulheres de ganho ou "ganhadeiras". A Feijoada de 10 de maio na casa de Dona Cabocla, que, do alto dos seus 103 anos de idade, canta e dança de forma deslumbrante nas festas que realiza em sua casa, das quais boa parte da comunidade participa. Tem ainda as Rodas de Samba espalhadas pelo bairro;

d. Aqueles que têm surgido mais recentemente, que estimulam a comunicação, a socialização e as trocas culturais entre os seus participantes, a exemplo dos saraus quinzenais na Casa da Música, localizada na Lagoa do Abaeté, com a participação de artistas do bairro e também convidados, ou ainda as caminhadas pelas Dunas, caminhada ao Bonfim, caminhada até a praia de Arembepe, dentre outras.

Essessãoapenasalgunsdosmaisimportantes eventos, sendo que inúmeros outros, de menor abrangência, mas já incorporados ao cotidiano do bairro, estão sendo constantemente criados e recriados, espalhando pela comunidade uma grande quantidade de festas e celebrações com as características citadas acima. Boaventura de
Sousa Santos nos diz que:

A recontextualização das identidades exige, nas condições atuais, que o esforço analítico e teórico concentre-se na elucidação das especificidades dos campos de confrontação e de negociação em que as identidades se formam e se dissolvem e na localização dessas especificidades nos movimentos de globalização do capital. (SANTOS, 1993, p. 43).

Nesse sentido, percebemos que algumas pessoas utilizam a liberdade das "artes do fazer", assim como diria Certeau (1994) em "A invenção do cotidiano", para agir e tentar mudar o que está posto. Inúmeras são as iniciativas que articulam a "fé" na mudança da realidade com a própria iniciativa em diminuir as distâncias entre as classes sociais. Vão construindo novas formas de sociabilidade e desafiando a globalização como vem sendo (im)posta.

Concordando com Gadotti (2004, p. 1), pedagogo e filósofo, "a vivência na cidade se constitui em um espaço cultural de aprendizagem permanente por si só". É o lugar onde as gerações se encontram, trocam experiências, conhecimentos e saberes necessários para se viver em sociedade, observam umas às outras e apreendem o padrão social de vida local que se modifica e também se repete ao longo dos anos.

Nessa mesma direção, e tomando a visão de Freire (2005, p. 127), a comunidade de Itapuã faz seus "círculos de investigação temática", em seus encontros e desencontros pelo bairro, nos quais a ação educativa se prolonga como ação cultural libertadora nos eventos e manifestações da cultura popular, que têm como marca a autonomia nos processos de organização, já que o poder público pouco participa na maioria das ações culturais desenvolvidas pela comunidade.

Nesse momento, nos inspiramos em Gohn (2008), socióloga que compreende a educação como um conceito amplo e associado ao de cultura, entendendo que a educação é adquirida no decorrer da vida. Na visão da autora, a 
cultura é interpretada como sendo "modos, formas e processos de atuação dos homens na história, onde ela se constrói" e que muda constantemente "influenciada por valores que se sedimentam em tradições e são transmitidos de uma geração para outra" (GOHN, 2008, p. 98). Dessa forma, a educação popular perpassa um protagonismo, uma maneira de fazer, de ensinar, de aprender que se baseia na realidade vivida e que é muito particular daquele contexto e região. São saberes e modos de vida que são aos poucos passados de um sujeito para o outro.

Libâneo (2005, p. 30), filósofo e estudioso da área da educação, ressalta que as mudanças contemporâneas têm contribuído para esse entendimento acerca da educação de forma mais ampla, que ocorre "em muitos lugares, institucionalizados ou não, sob várias modalidades". A educação é o conjunto de ações, processos, influências e estruturas que intervém no desenvolvimento humano de indivíduos e grupos na sua relação ativa com o meio natural e social, em um determinado contexto de relações entre grupos e classes sociais (LIBÂNEO, 2005). Assim, o desenvolvimento do ser humano e a ampliação das ferramentas de atuação nesse contexto cultural vai depender das interações sociais a que são expostos os indivíduos, desencadeando aprendizagens que serão fundamentais para ações de transformação social (VYGOTSKY, 1996).

Por conseguinte, os moradores do bairro de Itapuã demonstram estarem atentos aos acontecimentos e mudanças, ora "resistindo", utilizando-se de astúcia para agir, ora "conformando-se", quando se faz conveniente, exemplificando a análise que Chauí (1989) faz sobre o comportamento das camadas excluídas da população diante dos percalços que encontram na dura tarefa de sobreviver em uma sociedade excludente como a nossa.

Dessa maneira, os itapuanzeiros têm problematizado e se conscientizado sobre questões que afetam tanto a si mesmos como aos outros e a todo o espaço em que habitam. O exercício de aproximação com a memória possibilita trabalhar a imaginação dos sujeitos, e exemplos de situações e ações de indivíduos atuantes em um tempo passado envolvidos com táticas cotidianas servem de inspiração para o tempo presente e futuro.

Os participantes dessas manifestações culturais se inspiram nos antepassados locais para prosseguirem com a tradição. No entanto, com a modernidade, a ideologia hegemônica tira o foco dos rituais, produzindo as sociedades dessacralizadas da atualidade. Esse processo faz com que as comunidades que ainda resistem criem novas manifestações culturais, que têm o seu surgimento distinto das antigas manifestações que se pautavam na religiosidade apenas, embora essa característica continue a se fazer presente nessas novas configurações. Um exemplo disso é o que acontece na Festa de Itapuã, com o Café Nativo, evento que surgiu da iniciativa de Dona Nissú (senhora que esteve presente ativamente no processo de reconstrução cultural do bairro iniciado há alguns anos junto com Dona Francisquinha), buscando retomar o antigo sentido religioso da festa, mas, ao mesmo tempo, incorporando novas sociabilidades baseadas no encontro e na partilha. Um evento que acontece na madrugada do dia da Festa de Itapuã, precedido pelo cortejo do Bando Anunciador, que, desde as duas da madrugada, reúne centenas de pessoas que percorrem as ruas do bairro, acompanhadas de charangas e bandas de sopro, e que é finalizado justamente em frente à casa de Dona Nissú, onde, então, já com o raiar do dia, é servido a todos os participantes um abundante café da manhã, cujos ingredientes são trazidos pela própria comunidade dias antes, compartilhando uma grande refeição a céu aberto com todos os presentes, mesmo com aqueles que, por algum motivo, não tenham contribuído com sua parte. É a chamada "Alvorada", quando se inicia a Festa de Itapuã. 
Figura 3 - Bando Anunciador.

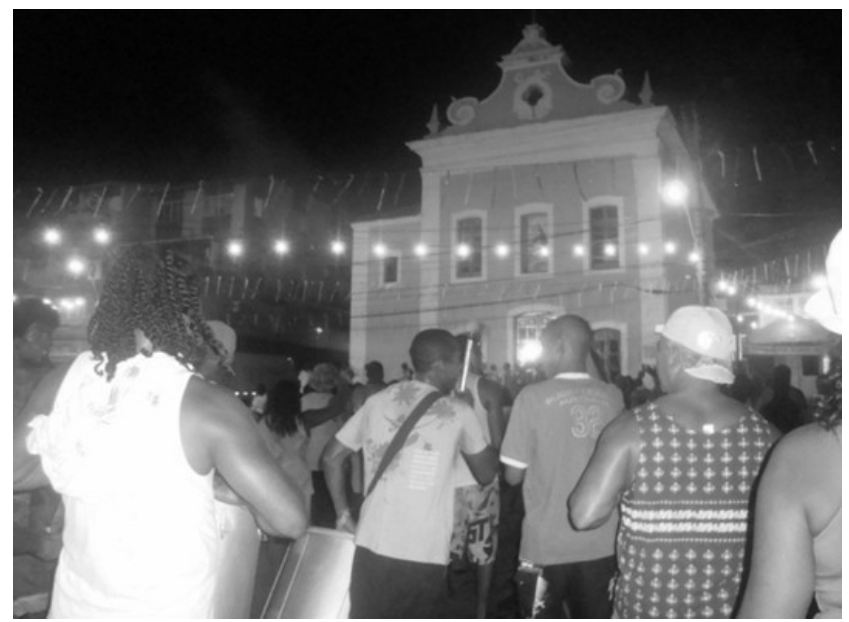

Fonte: Os autores (2010).

Assim, é preciso aguçar a audição para as falas, as músicas e os sons; ampliar a visão para os diferentes olhares - a escrita nos muros, as faixas penduradas nos postes, os símbolos, as cartolinas e miniquadros espalhados pelo bairro -; preparar o olfato para sentir o lugar, o cheiro de peixe, feijão, maresia e alfazema em dia de festa, para, assim, compreender as manifestações e criações artísticas, os gestos, as astúcias, as expressões da população e as formas de organização, pois elas são as maneiras encontradas pelas classes populares de dizer qual o caminho que pretendem seguir.

Assim os antigos e novos itapuanzeiros vão juntos, ressignificando suas práticas, retomando e atualizando tradições, reinventando formas de convivência, recriando antigos costumes, produzindo sentidos, recuperando histórias, memórias e personagens, restabelecendo os elos entre passado, presente e futuro enquanto celebram, festejam, rezam, comem, bebem, cantam e dançam.

\section{Considerações finais}

O processo de revitalização cultural por que tem passado o bairro de Itapuã tem relação com a necessidade de preservação, promoção e difusão da cultura, por parte de seus moradores, o que envolve recursos materiais e imateriais. É um processo constante de aprendizagem e tem relação com a economia quanto à forma criativa das pessoas produzirem, divulgarem e discutirem. São aprendizagens que estão vinculadas a outra lógica, esta distinta da mercantil por ter como princípios a solidariedade e a convivência entre as pessoas, levando-se em consideração os modos de vida do lugar, a criatividade de seus moradores e suas maneiras de resistir a toda essa lógica de mercado que predomina nas sociedades atuais.

Percebemos que as festas e outros eventos culturais são de extrema importância como formas de aproximar das pessoas, criar e fortalecer o espírito identitário e serem espaços para o exercício da cidadania, ou seja, lócus de aprendizados diversos, que envolvem a memória e história do lugar. A revitalização cultural precisa acontecer a todo o momento, a partir da luta dos moradores, dos grupos e das associações civis, artísticas e culturais, permitindo que os saberes e fazeres da comunidade possam ser mantidos ao mesmo tempo em que são transformados, devido às pressões do contexto 
global e das necessidades do contexto local em manter e passar adiante a sua identidade e sentimento de pertencimento às gerações.

$\mathrm{O}$ acesso dos sujeitos à cultura e aos saberes populares de maneira mais participativa contribui para que as pessoas possam se reconhecer na história como sujeitos/ atores, cujo papel continua a ser construído e reconstruído a todo instante. Isso pode refletir no desenvolvimento do sentimento de pertença, que independe do lugar onde o sujeito nasceu, mas se refere principalmente aonde este se identifica culturalmente, sendo imprescindível a interação, o conhecimento e o respeito para com o modo de vida do lugar.

As experiências vivenciadas por esses sujeitos, a partir do envolvimento com as atividades culturais e tradicionais de sua comunidade, nos fazem refletir sobre as possibilidades de ampliar o sentido do termo "educação", que, a partir do envolvimento com a cultura local, com o cotidiano, com os processos identitários (PAIS, 2009), permite expandir os espaços de aprendizagem para além dos muros da escola, possibilitando valorizar as vivências com a cultura do lugar como uma dimensão importante do desenvolvimento desses sujeitos, que acaba fortalecendo seu sentido de identidade, se reconhecendo como integrantes de um grupo social, desenvolvendo o seu sentido de pertencimento, criando momentos de aprendizagem social, cultural e da memória local e favorecendo a perpetuação das histórias, jeito de ser e acontecimentos do lugar.

$O$ forte sentido de pertencimento manifestado pelos moradores de Itapuã, sobretudo aqueles mais envolvidos com o processo de revitalização cultural do bairro, foi o que mais nos impressionou, mostrando pistas de como um processo de educação pautado nas relações culturais vivenciadas pelos sujeitos, tomando por referência o lugar onde vivem, faz florescer vínculos, estabelece novas sociabilidades e pode ser altamente significativo no que diz respeito à tomada de consciência desses sujeitos sobre suas identidades, sua capacidade de ação, sua autonomia, sua criatividade e sua liberdade.

\section{Referências}

BHABHA, H. O local da cultura. Tradução de Myriam Ávila, Eliana Lourenço de Lima Reis e Gláucia Renate Gonçalves. Belo Horizonte: UFMG, 2005.

CASTELLS, M. A era da informação: economia, sociedade e cultura - o poder da identidade. v. 2. São Paulo: Paz e Terra, 1999.

CERTEAU, M. de. A invenção do cotidiano: 1. artes de fazer. Tradução de Ephraim Ferreira Alves. Petrópolis: Vozes, 1994.

Chauí, M. Conformismo e resistência: aspectosaspectos da cultura popular no Brasil. 4. ed. São Paulo: Brasiliense, 1989.

FREIRE, P. Educação e mudança. 31. ed. São Paulo: Paz e Terra, 2008.

Pedagogia do oprimido. Rio de Janeiro: Paz e Terra, 2005.

GADOTTI, M. A. escola na cidade que educa. São Paulo: Cortez; IPF, 2004.

GOHN, M. G. da. Educação não-formal e cultura política. São Paulo: Cortez, 2008. 
HALL, S. A identidade cultural na pós-modernidade. 11. ed. Tradução de Tomaz Tadeu da Silva e Guaracira Lopes Louro. Rio de Janeiro: DP \&A, 2006.

HOBSBAWM, E.; RANGER, T. (Org.). A invenção das tradições. Rio de Janeiro: Paz e Terra, 1997. LIBÂNEO, J. C. Pedagogia e pedagogos: para quê? 8. ed. São Paulo: Cortez, 2005.

MAGNANI, J. G. C. Festa no pedaço: cultura popular e lazer na cidade. 3. ed. São Paulo: Hucitec; Uneso, 2003.

PAIS, J. M. Sociologia da vida quotidiana: teoria, métodos e estudos de caso. 4. ed. Lisboa: Imprensa de Ciências Sociais, 2009.

SANTOS, B. S. de. Modernidade, identidade e a cultura de fronteira. Tempo Social: Rev. Sociol. USP, São Paulo, v. 5, n. 1-2, p. 31-52, 1993.

SANTOS, M. Por outra globalização: do pensamento único à consciência universal. 18. ed. Rio de Janeiro: Record, 2009.

VELHO, G. Individualismo e cultura: notas para uma antropologia da sociedade contemporânea. 4. ed. Rio de Janeiro: J. Zahar, 1997.

VYGOTSKY, L. S. A formação social da mente. Rio de Janeiro: Martins Fontes, 1996.

Submetido em 14 de abril de 2015.

Aprovado em 4 de julho de 2015. 